\title{
Self-esteem and negative ideal selves in adults ${ }^{1}$
}

\author{
YUMI ENDO
}

Joetsu University of Education, Joetsu, Nizgata 943

\begin{abstract}
The purpose of the present study was to generalize the following findings which were gained from previous studies whose subjects were college students: Both positive and negative ideal selves (the selves that I would never like to become) can be standards of self-evaluation. Subjects of this study were school teachers. Their ages ranged from 27 to 47 . The results of various self ratings and self-esteem scale showed that positive/negative ideal-actual discrepancy scores significantly correlate with self-esteem. These results suggested that negative ideal selves as well as positive ideal selves are standard for selfesteem even for adults (who have their social roles and have cleared to some extent a minimum standard of social life).
\end{abstract}

Key words : positive ideal selves, negative ideal selves, discrepancy scores, self-esteem.

Traditionally, discrepancy scores between ideal self and actual self have been associated with low self-esteem (e.g. Hoge \& McCarthy,1983; Okada,1987; Suga,1975). The basic idea was that self-esteem is the outcome of comparison between actual self and ideal self as a self-evaluative standard. But, many researchers have pointed out that research using discrepancy scores have not produced convincing results (Endo, 1991; Kato,1960; Hoge \& McCarthy, 1983; Wylie, 1974). And, Hoge and McCarthy (1983) have reached a conclusion that the discrepancy measure itself is of limited value in predicting self-esteem.

James (1890) and Rosenberg (1965) have emphasized that self-evaluation occurs within an individual's unique framework of evaluative standards. Endo (1992a) and Moretti and Higgins (1990) have pointed out that individuals differ in the importance they place on actual-self attributes for self-esteem, and that the default of idiographic standpoint to reflect such an individual difference would be one of the reasons for the vulnerability of discrepancy measure.

In fact, using spontaneous subject-generated items instead of a standard set of person-

1 This research was supported in part by a Grant-inAid for Scientific Research (No. 02610039), Ministry of Education, Science and Culture of Japan, to Yumi Endo. ality items for all subjects (Moretti \& Higgins, 1990), or using only selected important items for each individuals based on rating score for ideal self (weighted discrepancy score) (Endo, 1992a), they found that individualized discrepancy score, rather than general total discrepancy score, has strongly correlated with self-esteem.

Therefore, a conclusion that the discrepancy measure itself is of limited value in predicting self-esteem may be premature. One of problems in research on discrepancy is in the assumption that positive characteristics for one person is also positive for other person, and in the nomothetic measurement corresponding to it.

Another problem is that negative aspects have seldom been investigated in these area. In general, it has been thought that positive and negative aspects are just the reverse of each other. But recently, various reseachers have pointed that many attriubutes in personality are not unidimensional (e.g. Bem, 1974). And, positive and negative aspects coexist within a personality (Kuwabara, 1986).

Endo (1992b) and Ogilvie (1987) have pointed that we have negative ideal selves or undesired self which are to be avoided (i.e., they are the selves that I would never like to become), as well as positive ideal selves which 
are to be approached (i.e., they are the selves that I would like to become), and both positive and negative ideal selves can be standards of self-evaluation. Endo (1992b) suggested self-esteem is a function of distance of how close I am to the person who I would like to be and also of how far I am from the person who I do not want to be.

The previous research findings about negative ideal selves were obtained only from adolescent subjects. However, adolescents tend to be more concerned about negative aspects of themselves (Miyazawa,1988). Furthermore, most adults have their jobs or social roles and to some extent they may have established adjustment. Then, it is possible that adults do not care for negative ideal selves as minimum standard. In such a case, it would be difficult to find correlation between self-esteem and negative ideal-actual discrepancy scores in adults. The purpose of the present study was to investigate whether those findings can be generalized to adults.

\section{Method}

Subjects. Subjects' ages ranged from 27 to 47 (the average $=33.67, S D=5.00)$. Subjects (77 males, 12 females) were obtained from graduate course in School Education. They used to be (elementary, junior high, or high) school teachers by profession. When the present study was conducted, they were graduate students for higher educational training.

Questionnaire. Graduate students were asked to make items relating to self-concept in seven categories (life-style, family, relationship with others, personality, occupation or academic achievement, physical, possessions). Of 89 items, 25 positive $(P$-item $)$ and 25 negative items $(\mathcal{N}$-item) were adopted into a questionnaire.

Procedure. Instruction for self-ratings was as follows: positive ideal-self (How I would like to be?) / negative ideal-self (How I hope to never be?) / actual self (How I am most of the time?). For positive ideal self rating, $P$ items were used. $\mathcal{N}$-items were used for nega- tive ideal self ratings, and $P$-items and $\mathcal{N}$ items for actual self rating. Subjects were asked to rate how descriptive each item was for themselves on 5-points scale. Self-esteem was measured by Rosenberg Self-Esteem Scale (translated by Hoshino 1970). Subjects were asked to rate the self-descriptiveness of 10 items on a scale from 1 (strongly disagree) to 5 (strongly agree). A total self-esteem score ( $S E$-score) was derived by summing ratings across the 10 items. The mean was 32.0 $(S D=6.2)$.

\section{Result}

\section{Self-Esteem and Total Discrepancy Score}

To calculate the total discrepancy score in $P$-items ( $D p$-score), positive ideal self were compared with (positive) actual self. That is, $D p$-score was obtained by a formula; $D p=\sqrt{\sum d p^{2}}$. Total discrepancy score in $\mathcal{N}$ items were obtained in the similar way; $D n=\sqrt{\sum d n^{2}}$.

To test the first hypothesis that both positive and negative ideal self can be standards of self-esteem, $S E$-score was correlated with $D p$-score and $D n$-score. The correlation was $-.308(p<.001)$ for $D p$-score, and was .251 $(p<.05)$ for $D n$-score.

The correlation between $D p$-score and selfesteem, or the correlation between $D n$-score and self-esteem, may be due to the correlation between $D p$-score and $D n$-score, because the both discrepancy scores were obtained from the same individuals. Partial correlations controlling for each other were computed. The partial correlations were -.317 $(p<.01)$ for $D p$-score, and $.262(p<.05)$ for $D n$-score.

As predicted, not only $D p$-score but also $D n$-score are correlated with self-esteem.

Self-Esteem and Weighted Discrepancy Score

The weighted discrepancy score (Dpi for positive items; Dni for negative items) was calculated as the distance between positive/ negative ideal self and actual self in weighted items which a subject gave a high rating score of 5 in positive ideal self and negative 
Table 1

Relation of discrepancy score to self-esteem

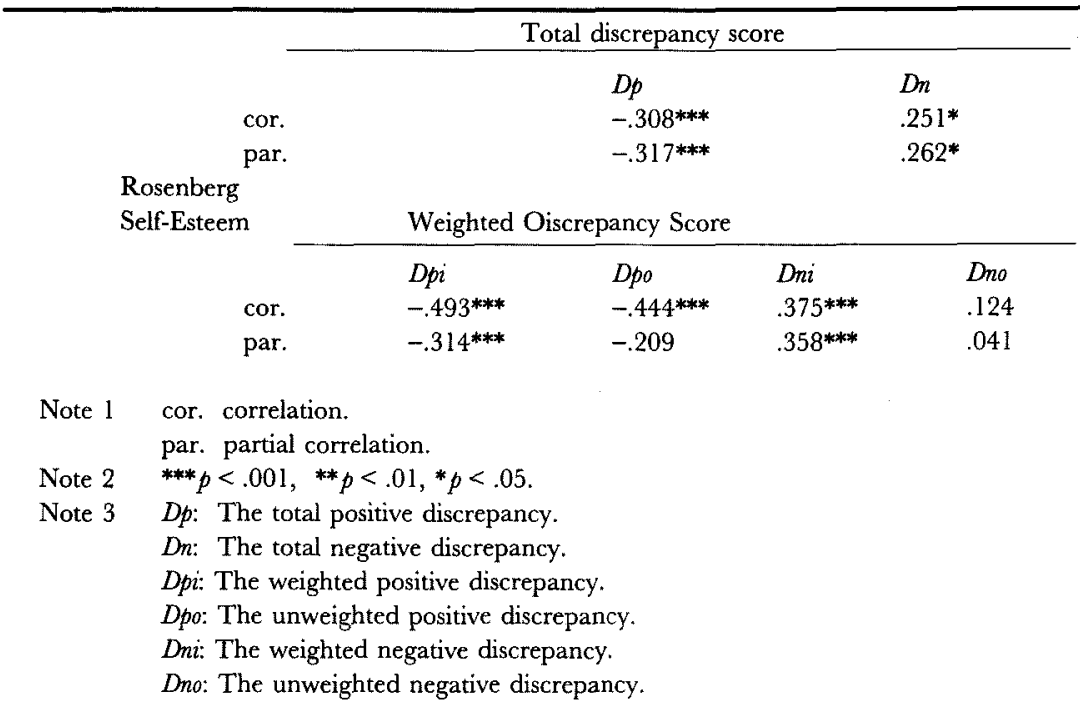

ideal self ratings. The unweighted discrepancy score ( $D p o$ for positive items; Dno for negative items) was the distance between positive/negative ideal self and actual self in unweighted items which a subject gave lower rating scores (4 and below) in positive and negative ideal self ratings.

$D p i$ score were calculate by a formula; $D p i=\sqrt{\sum d p^{2} / n i}$. $(n i=$ the number of items which were rated as 5). And in the same way, the other 3 measures were calculated. $S E$ score was correlated with these 4 scores.

The results of these analyses are presented in Table 1. Correlations for $D p i, D_{p o}$ and $D n i$ scores reached to significant level. The weighted discrepansy scores were significantly correlated with the unweighted discrepancy scores $(r=.805$ between $D p i$ and $D p o, r=.522$ between $D n i$ and Dno), partial correlations controlling each other were computed. Partial correlation between $D p i$ and self-esteem was $-.314(p<.001)$, between $D p o$ and self esteem was -.209 (ns). Partial correlation between Dni and self-esteem was $.358(p<.001)$, between $D n o$ and self-esteem was $.041(n s)$. That is, in both positive and negative aspects, only the weighted discrepancy scores were significantly correlated with self-esteem.

The correlations between the total discrepansy score and self-esteem, and the weighted discrepancy score and self-esteem are significantly different, $t(86)=3.205$, $p<.01$ in positive aspect. In negative aspect, the correlation between the weighted discrepancy score and self-esteem is larger than the correlation between the total discrepancy score and self-esteem, though the difference among them did not reach significant level, $t(86)=1.272, n s$.

\section{Discussion}

The present study, whose subjects were adults, revealed that the negative ideal-actual self discrepancy as well as the positive idealactual discrepancy is correlated with self-esteem. These results offer stronger support that both positive and negative ideal self can be standards to which actual self is compared for self-evaluation. These phenomena are seen not only in adolescents but also in adults. 
In other words, to assess their self-esteem even adults use negative ideal self as a standard (i.e., how distant they are from negative ideal images of themselves). As mentioned already, subjects of the present study were school teachers. They have their social roles and belong to the middle class. In some respects, they have cleared a minimum standard of social life. But it is still important for them to know how they are unlike their negative ideal images.

The results also support the conclusion that the individualized discrepancy is a significant predictor of self-esteem. Traditionally, it has been thought that high selfesteem is almost synonymous with total high positiveness of actual self on a standard set of personality rating items (e.g. Oyserman \& Markus, 1990). However, results in the current study suggest that high rating scores on positive attributes for the actual self are not strongly predictive of high self-esteem unless the individual sets importance on those attributes. Similarly, high rating scores on negative attributes for actual self are not necessarily predictive of low self-esteem unless the individual sets importance on those attributes in relation to negative ideal self. Total discrepacy score may weaken predicting power of self-esteem because it is based on both important and non-important dimensions for each person.

It has been reported that there are sexdifferences in self-concept or self-esteem (Kato \& Sorita,1961; Suga, 1975; Sawazaki, Manita, \& Kodama, 1981; Yamamoto, Matsui, \& Yamanari, 1982). Because the numbers of male and female subjects in the present study were not balanced, another study may be required before a firm conclusion can be reached.

We have both positive ideal selves and negative ideal selves which are not the reverse of the former (Endo, 1992b). Then, it is required that more researches on negative ideal selves, apart from positive ideal selves, will be done: How it is structured? What is the content? How it is developed?

\section{Reference}

Bem, S. 1974 The measurement of psychological androgyny. Joumal of Consulting and Clinical Psychology, 42 , 155-162.

Endo, Y. 1991 Recent topics of ideal self studies: The relation between the self-concept and adjustment. Bulletin of Joetsu University of Education, 10, (2), 19-36. (In Japanese)

Endo, Y. 1992a Personalized standard of self-esteem. Japanese Joumal of Educational Psychology. (In press)

Endo, Y. 1992b Negative ideal-self as a standard of selfesteem. Japanese Joumal of Psychology. (In press)

Hoge, D.R., \& MaCarthy, J.D. 1983 Issues of validity and reliability on the use of real-ideal discrepancy score to measure self-regard. Joumal of Personality and Social Psychology, 44, 1048-1055.

Hoshino, M. 1970 Affect and education (II). Child Psychology, 8, 161-193. (In Japanese)

James, W. 1890 The principles of psychology. New York: Dover. (Republished 1950)

Kato, T. 1960 A review of studies on adjustment from the self-concept. Japanese Journal of Psychology, 31, 53-63. (In Japanese)

- Kato, T., \& Sorita, T. 1961 A study on the self, ideal self and ideal opposite sex concept of the adolescent. Japa nese Joumal of Educational Psychology, 9, 1-8. (In Japanese)

Kuwabara, T. 1986 An approach to measure the "twosideness of personality": The revision of "two-side personality scale". Japanese Joumal of Educational Psychology, 34, 31-38. (In Japanese with English abstract)

Miyazawa, S. 1988 A longitudinal study of self-acceptance in junior high school girls. Japanese Joumal of Educational Psychology, 36, 258-263. (In Japanese with English abstract)

Moretti, M.M., \& Higgins, E.T. 1990 Relating self-discrepancy to self-esteem: The contribution of discrepancy beyond actual self ratings. Joumal of Experimental Social Psychology, 26, 108-123.

Ogilvie, D.H. 1987 The undesired self: A neglected variable in personality research. Joumal of Personality and Social Psychology, 52, 379-385.

Okada, T. 1987 The ego ideal in male adolescence and its process of formation. Japanese Joumal of Educational Psychology, 35, 116-121. (In Japanese with English abstract)

Oyserman, D., \& Markus, H. 1990 Possible selves and delinquency. Joumal of Personality and Social Psychology, 59, 112-125.

Rosenberg, M. 1965 Society and the adlescent self-image. Princeton University Press.

Sawazaki, T., Manita, A., \& Kodama, M. 1981 A study on self-acceptance in adolescence (1)-Preliminary report with high school pupils. Bulletin of Consultation and School Psychology, 19, 43-60. (In Japanese) 
Suga, S. 1975 A study on self-esteem and relationship with others in adolescent. Japanese Joumal of Educational Psychology, 23, 19-24. (In Japanese)

Wylie, R. 1974 The self-concept: $A$ review of methodological considerations and measuring instruments. Lincolon, NB:
University of Nebraska Press.

Yamamoto, M., Matsui, Y., \& Yamanari, Y., 1982 Structure of perceived selves. Japanese Joumal of Educational Psychology, 30, 64-68. (In Japanese)

(Received June 11, 1991; accepted March 14, 1992) 